\title{
General Practitioners Recognizing Alcohol Dependence: A Large Cross-Sectional Study in 6 European Countries
}

\author{
Jürgen Rebm, PbD \\ Allaman Allamani, MD \\ Roberto Della Vedova, MD \\ Zsuzsanna Elekes, DSc \\ Andrzej Jakubczyk, MD \\ Inga Landsmane, MD \\ Jakob Mantbey, MS \\ José Moreno-España, MD \\ Lars Pieper, $\mathrm{PbD}$ \\ Charlotte Probst, MS \\ Sigita Snikere, MSc \\ Pierluigi Struzzo, MD \\ Fabio Voller, MC \\ Hans-Ulricb Wittchen, PbD \\ Antoni Gual, MD* \\ Marcin Wojnar, MD* \\ *Joint last authorship.
}

Conflicts of interest: Probst, Voller, Manthey, Moreno-España, Pieper, Vedova, Snikere, and Elekes report none. See Funding support statement.

\section{CORRESPONDING AUTHOR}

Jakob Manthey, MS

Institute of Clinical Psychology and Psychotherapy \& Center of Clinical Epidemiology and Longitudinal Studies (CELOS)

Technische Universität Dresden

Chemnitzer Str. 46

01187 Dresden, Germany

johann_jakob.manthey@mailbox.

tu-dresden.de

\begin{abstract}
PURPOSE Although alcohol dependence causes marked mortality and disease burden in Europe, the treatment rate is low. Primary care could play a key role in reducing alcohol-attributable harm by screening, brief interventions, and initiating or referral to treatment. This study investigates identification of alcohol dependence in European primary care settings.
\end{abstract}

METHODS Assessments from 13,003 general practitioners, and 9,098 interviews $(8,476$ joint number of interviewed patients with a physician's assessment) were collected in 6 European countries. Alcohol dependence, comorbidities, and health service utilization were assessed by the general practitioner and independently using the Composite International Diagnostic Interview (CIDI) and other structured interviews. Weighted regression analyses were used to compare the impact of influencing variables on both types of diagnoses.

RESULTS The rate of patients being identified as alcohol dependent by the CIDI or a general practitioner was about equally high, but there was not a lot of overlap between cases identified. Alcohol-dependent patients identified by a physician were older, had higher rates of physicial comorbidity (liver disease, hypertension), and were socially more marginalized, whereas average consumption of alcohol and mental comorbidity were equally high in both groups.

CONCLUSION General practitioners were able to identify alcohol dependence, but the cases they identified differed from cases identified using the CIDI. The role of the CIDI as the reference standard should be reexamined, as older alcohol-dependent patients with severe comorbidities seemed to be missed in this assessment.

Ann Fam Med 2015;13:28-32. doi: 10.1370/afm.1742.

\section{INTRODUCTION}

lcohol consumption is a major risk factor for mortality and disability $\triangle$ in Europe, ${ }^{1,2}$ and alcohol dependence as been shown to account for a 1 great proportion of this burden. ${ }^{3,4}$ Alcohol dependence can be characterized as a maladaptive pattern of alcohol use that leads to clinically significant impairment or distress. ${ }^{5}$ Despite the associated high level of disease burden, alcohol dependence has the lowest treatment rate among all major mental disorders at an estimated $10 \%$ for Europe. ${ }^{3,6-8}$

General practitioners have been identified as key for improving access to care services ${ }^{9}$ for alcohol-dependent patients in 3 ways: recognition and diagnosis, provision of interventions, and referral to specialized services. In the early 1990s, however, results of a large-scale World Health Organization study in primary care centers in 14 countries (including 7 European countries) showed that primary care physicians recognized only about $50 \%$ of mental disorders, ${ }^{9}$ and alcohol use disorders were no exception.

We wanted to compare how alcohol dependence is recognized in primary care facilities in 6 European countries based on the reference standard for assessing alcohol use disorders, the World Health Organization Composite International Diagnostic Interview (CIDI). 


\section{METHODS}

\section{Setting and Participants}

Primary care practices were representative for the following regions/countries: Catalonia (Spain), FriuliVenezia Giulia region (Italy 1) i Hungary, Latvia, Łódź, and Podkarpackie Province (Poland) $)_{i}$ Saxony and Berlin state (Germany); and Tuscany region (Italy 2). Patients, either scheduled for a given day or as a stratified random subsample, were asked to participate in the patient interview conducted by trained interviewers with varying professional backgrounds (eg, medical doctors, students, psychologists). Stratification was based on the general practitioner's assessment, oversampling patients with perceived alcohol problems. Patients had to meet the following eligibility criteria: 18 to 64 years of age and coming to the primary care practice for a consultation with a physician. A detailed listing of the sampling procedure can be found in Supplemental Appendix 1.

\section{Variables and Measurement}

The physicians assessed the following areas: demographics, health problems, current alcohol use, including alcohol dependence and alcohol abuse, and alcohol treatment (Supplemental Appendix 2). For the patient interview, we relied on the alcohol use disorders section of the CIDI, an instrument that is used in most international general population studies. ${ }^{10}$ The CIDI first assessed the quantity and frequency of alcohol consumption and subsequently the criteria for alcohol use disorders according to the Diagnostic and Statistical Manual of Mental Disorders (4th Edition) (DSM-IV). ${ }^{5}$

In addition, the following instruments were used: Kessler Psychological Distress Scale, ${ }^{11,12}$ World Health Organization Disability Assessment Schedule 2.0,13,14 the health services utilization questionnaire from the alcohol treatment trials in the United Kingdom, ${ }^{15}$ and open-ended questions about health care utilization.

\section{Statistical Methods}

Descriptive statistics were used to discriminate predictors underlying diagnosis, and linear and logistic regressions, as well as a multinomial logit analysis, were performed. All analyses were adjusted for study design and conducted using Stata 12.0 (StataCorp LP).

More information on methodological aspects of the study can be found elsewhere. ${ }^{16}$ All concerned committees obtained ethics approval.

\section{RESULTS}

\section{Participants and Descriptive Data}

The refusal rates were $56.4 \%$ for the physicians and $17.8 \%$ for the patients. Overall, we collected physicians' assessments of 13,003 patients $(5,461$ for men and 7,542 for women) and 9,098 interviews (3,715 for men and 5,383 for women). Sample characteristics can be found in Supplemental Appendix 3. More women attended primary care practices during in the assessment period, and younger age-groups were underrepresented. The 12 -month prevalence of drinking was high $(64.4 \%$; $95 \% \mathrm{CI}, 63.4 \%-65.4 \%)$.

\section{Prevalence of Alcohol Use Disorders}

The 12-month prevalence of alcohol dependence was around $5 \%$, when assessed by the physician $(5.1 \%$; $95 \% \mathrm{CI}, 4.7 \%-5.5 \% ; \mathrm{n}=13,003)$ or the CIDI interview $(5.5 \%, 95 \% \mathrm{CI}, 5.1 \%-6.0 \% ; \mathrm{n}=9,098)$. Although the physician assessment and the CIDI yielded a similar prevalence, they identified different patient populations. Fewer than one-fifth of the cases were identified by both methods (Figure 1). The physician and/or CIDI identified alcohol dependence rate resulted in an overall prevalence of $8.7 \%$ (95\% CI, 8.1\%-9.3\%).

Although patients with alcohol dependence had a substantially poorer social, morbidity, and disability profile, their profiles differed depending on whether their alcohol dependence status was defined by the CIDI or a physician (Table 1).

After the multinomial logit and logistic regression analyses, older age, greater unemployment, lower education, and more hypertension and liver comorbidities were associated with a physician's diagnosis (Supplemental Appendix 4). In terms of DSM-IV criteria, patients among the physician-diagnosed cases continued to drink more often despite social problems.

\section{DISCUSSION}

The results confirm that in Europe alcohol dependence is common and disabling among primary care practices

\section{Figure 1. Venn diagram of alcohol dependence determined by a general practitioner's assessment or by the CIDI based on self-report.}

Population with interviews and GP assessment $(n=8,476)$

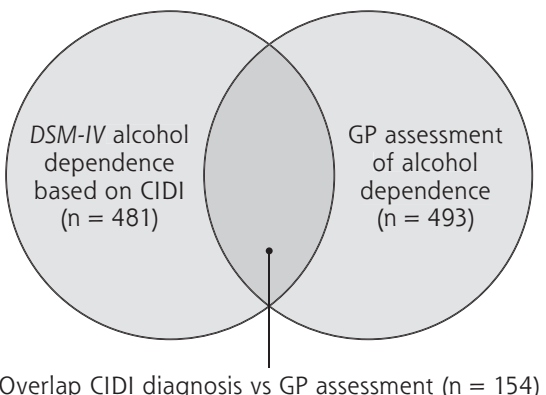

CIDI = Composite International Diagnostic Interview; DSM-IV = Diagnostic and Statistical Manual of Mental Disorders (4th Edition); GP = general practitioner. 
$(8.7 \%),{ }^{8,17}$ and it is twice as prevalent in primary care than in general population studies $\left(3.4 \%{ }^{18}\right)$. Compared with the CIDI, general practitioners identified more patients with alcohol dependence, and their cases seemed to be more severe (same level of drinking and mental problems, but higher level of physical problems and social disintegration). This finding raises the questions about validity of CIDI and its status as a reference standard.

Although this study is one of the few based on a representative register sampling, the $56.4 \%$ of general practitioners who refused to participate might have had different characteristics. When compared with other studies of general practitioners that used probabilistic sampling techniques, however, our response rate can be considered satisfactory. ${ }^{19,20}$

A major finding of this study is that the CIDI was not as successful as a physician in identifying cases of alcohol dependence in older patients. These patients had considerable physical comorbidities, and the CIDI, which was conceptualized for mental diagnoses, includes physical comorbidity only indirectly (drinking despite physical problems). The CIDI also evidenced major limitations with older patients in studies of depression, resulting in an artificially lower prevalence. ${ }^{21}$ It is possible the different findings of the CIDI and the physicians were a result of the 12-month frame time we used; some cases might have met full alcohol dependence criteria earlier but not later in the study, resulting in negative CIDI diagnostic status but a positive physician's diagnosis. ${ }^{21} \mathrm{On}$ the other hand, general practitioners may miss alcohol dependence in younger patients because they do not visit primary care practices as frequently as older adults.

More efforts are needed to enhance general practitioners' recognition and intervention rates in younger adults. These patients might benefit from standardized screening, as well as brief interventions to reduce drinking. ${ }^{22,23}$ Because older alcohol-dependent patients have relatively high levels of physical and mental comorbidity, the physician will need to decide whether to provide formal treatment in the office setting or refer for specialized care.

Although effective options exist for treating alcohol dependence, including pharmacotherapy, ${ }^{24,25}$ there are substantial barriers to applying these options in primary care. ${ }^{26,27}$ We see no reason why primary care physicians could not conduct most treatments for less severe cases of alcohol dependence. Incentive structures would need to be established to allow such treatment within their busy schedules. ${ }^{28}$ General practitioners' detection and intervention rates could be improved by routinely checking patients' alcohol consumption, much as they do for hypertension, by suggesting options for reduction, and by intervening if certain thresholds are crossed. ${ }^{29}$ The physicians in our study were able to detect cases of alcohol dependence in need of treatment. Now the necessary incentive structures should be established so they can deliver interventions or increase referrals to specialized care. ${ }^{30}$ 
Interviewed ${ }^{\mathrm{a}}$

( $n=3,449$ Men; $n=5,027$ Women)

\begin{tabular}{|c|c|c|c|c|c|c|c|}
\hline \multicolumn{2}{|c|}{ Diagnosis by GP Only } & \multicolumn{2}{|c|}{ Diagnosis by GP and CIDI } & \multicolumn{2}{|c|}{ Diagnosis by CIDI Only } & \multirow[b]{2}{*}{$P$ Value $^{b}$} & \multirow[b]{2}{*}{$P$ Value } \\
\hline Male & Female & Male & Female & Male & Female & & \\
\hline $5.6(4.8-6.3)$ & $1.9(1.5-2.2)$ & $3.1(2.5-3.7)$ & $0.6(0.4-0.8)$ & $5.9(5.1-6.7)$ & $2.4(1.9-2.8)$ & - & - \\
\hline $50.9(10.9)$ & $50.1(12.1)$ & $49.8(11.7)$ & $48.8(12.1)$ & $38.3(13.2)$ & $38.2(13.5)$ & $<.0001^{d}$ & $<.0001^{\mathrm{d}}$ \\
\hline $5.3(2.1-8.4)$ & $7.9(2.6-13.3)$ & $10.8(4.7-16.8)$ & $10.5(0.0-21.8)$ & $9.7(5.6-13.8)$ & $12.2(6.3-18.1)$ & - & - \\
\hline $58.8(52.1-65.5)$ & $50.6(40.9-60.2)$ & $48.5(39.3-57.7)$ & $38.5(21.4-55.6)$ & $61.0(54.3-67.8)$ & $66.6(58.1-75.1)$ & - & - \\
\hline $36.0(29.4-42.5)$ & $41.5(31.9-51.1)$ & $40.7(31.7-49.8)$ & $51.0(33.0-68.9)$ & $29.3(23.0-35.6)$ & $21.2(13.9-28.6)$ & .0219 & .0033 \\
\hline $27.8(21.9-33.8)$ & $36.6(27.4-45.8)$ & $34.0(25.4-42.7)$ & $38.9(21.4-56.4)$ & $15.6(10.5-20.6)$ & $17.3(10.5-24.1)$ & $.0021^{\mathrm{e}}$ & $<.0001^{\mathrm{d}}$ \\
\hline $59.9(53.3-66.5)$ & $54.3(44.6-63.9)$ & $69.1(60.5-77.8)$ & $76.9(61.6-92.2)$ & $58.8(51.9-65.6)$ & $47.4(38.3-56.4)$ & $.0010^{e}$ & .0546 \\
\hline $27.2(6.7)$ & $27.0(5.8)$ & $25.8(4.8)$ & $24.7(6.3)$ & $26.0(4.5)$ & $23.4(4.8)$ & .0072 & .0697 \\
\hline $45.2(38.6-51.9)$ & $45.0(35.4-54.6)$ & $43.7(34.7-52.8)$ & $54.4(36.5-72.2)$ & $19.1(13.6-24.6)$ & $12.0(6.3-17.7)$ & .0623 & $.0005^{d}$ \\
\hline $19.5(14.1-24.8)$ & $20.4(12.4-28.5)$ & $32.2(23.6-40.8)$ & $20.0(6.0-33.9)$ & $1.6(0.0-3.4)$ & $0.8(0.0-2.2)$ & $<.0001^{\mathrm{d}}$ & $<.0001^{\mathrm{d}}$ \\
\hline $10.9(6.7-15.1)$ & $18.6(10.8-26.4)$ & $27.3(19.2-35.5)$ & $19.9(5.4-34.4)$ & $7.2(3.6-10.7)$ & $14.2(7.6-20.8)$ & $.0002^{\mathrm{d}}$ & .7108 \\
\hline $16.8(11.9-21.8)$ & $20.3(12.7-27.8)$ & $32.0(23.4-40.6)$ & $33.1(16.2-50.0)$ & $10.2(6.0-14.4)$ & $19.0(11.7-26.4)$ & $<.0001^{d}$ & .4873 \\
\hline $8.0(4.5-11.6)$ & $8.6(3.2-14.1)$ & $21.5(14.0-29.0)$ & $21.5(7.0-36.1)$ & $8.6(4.7-12.6)$ & $16.3(9.5-23.2)$ & $.0002^{d}$ & .0569 \\
\hline $8.3(8.1)$ & $10.3(8.6)$ & $14.0(8.6)$ & $14.3(9.0)$ & $9.4(7.6)$ & $11.9(9.0)$ & $<.0001^{d}$ & .0084 \\
\hline $11.8(16.0)$ & $14.0(14.7)$ & $19.6(19.1)$ & $19.3(18.5)$ & $12.3(15.3)$ & $12.4(14.9)$ & $<.0001^{d}$ & .2727 \\
\hline $2.3(7.3)$ & $2.0(6.1)$ & $4.8(9.0)$ & $2.4(3.4)$ & $2.1(5.8)$ & $2.3(6.1)$ & $.0025^{e}$ & .8362 \\
\hline $50.3(38.8)$ & $46.9(36.1)$ & $87.6(69.9)$ & $62.7(58.6)$ & $52.6(50.1)$ & $42.2(50.3)$ & $<.0001^{d}$ & .5451 \\
\hline $9.3(4.2-14.5)$ & $10.8(0.0-22.5)$ & $32.4(22.5-42.3)$ & $22.2(4.9-39.4)$ & $13.7(7.7-19.7)$ & $8.8(1.4-16.2)$ & $<.0001^{d}$ & .3814 \\
\hline $8.5(3.4-13.6)$ & $15.0(1.3-28.8)$ & $28.8(19.2-38.4)$ & $21.3(4.5-38.1)$ & $17.1(10.5-23.7)$ & $7.2(0.3-14.0)$ & $<.0001^{d}$ & .8955 \\
\hline
\end{tabular}

a Data were weighted with inverse sampling probabilities.

${ }^{b}$ Compares group means of patients diagnosed by GP and CIDI with patients diagnosed either by CIDI or GP only; controlled for age and sex.

' Compares group means of patients diagnosed by GP only with patients diagnosed by CIDI only; controlled for age and sex.

${ }^{d} P$ values significant for Bonferoni-adjusted thresholds: $P<.01 / 16=.000625$.

e $P$ values significant for Bonferoni-adjusted thresholds: $P<.05 / 16=.003125$.

${ }^{\mathrm{f}} \mathrm{K} 10$ cutoff for severe mental distress was 21 points in a total score ranging from 0 to 40 , where higher scores indicate more severe distress.

g WHODAS 2.0 total score ranges from 0 to 100, where higher scores indicate higher level of disability.

${ }^{\mathrm{h}}$ Analyses were computed on patients reporting ethanol use of at least $10 \mathrm{~g} / \mathrm{d}$ (remaining patients with alcohol dependence were abstaining).

To read or post commentaries in response to this article, see it online at http://www.annfammed.org/content/13/1/28.

Key words: alcoholism; alcohol dependence; DSM-IV; general practitioner; primary healthcare; therapy

Submitted June 30, 2014; submitted, revised, September 9, 2014; accepted October 2, 2014.

Author affiliations: Centre for Addiction and Mental Health, Toronto, Canada (J.R.); Addiction Policy, Dalla Lana School of Public Health, University of Toronto, Toronto, Canada (J.R.); Institute of Medical Science, University of Toronto, Faculty of Medicine, Toronto, Canada (J.R.); Department of Psychiatry, University of Toronto, Toronto, Canada (J.R.); Institute of Clinical Psychology and Psychotherapy \& Center of Clinical Epidemiology and Longitudinal Studies (CELOS), Technische Universität Dresden, Dresden, Germany (J.R., J.M., L.P., C.P., H-U.W.); Agenzia Regionale di Sanità Toscana, Villa la Quiete alle Montalve, Firenze, Italy (A.A., F.V.); Regional Centre for the Training in Primary Care (Ceformed), Monfalcone (GO), Italy (R.D.V., P.S.); Center for Study and Research in General Practice (CSeRMEG), Via Praga, 22, 20052 Monza (MI), Italy (R.D.V.); Corvinus University of Budapest, Budapest, Hungary (Z.E.); Department of Psychiatry, Medical University of Warsaw, Warsaw, Poland (A.J., M.W.); Riga Centre of Psychiatry and Addiction Medicine, Riga, Latvia (I.L.); Fundació Clínic per a la Recerca Biomèdica, Barcelona, Spain (J.M-E.); Addictions Unit, Psychiatry Department, Neurosciences Institute, Hospital Clinic, Barcelona, Spain (J.M-E., A.G.); Institute of Sociological Research, Riga, Latvia (S.S.); Institut d'Investigacions Biomèdiques August Pi i Sunyer (IDIBAPS), Barcelona, Spain (A.G.); Red de Trastornos Adictivos (RTA RETICS), Instituto de Salud Carlos III, Barcelona, Spain (A.G.); Department of Psychiatry, University of Michigan, Ann Arbor, Michigan (M.W.).

Authors' contributions: J.R., A.G., and M.W. conceptualized the study and served as principal investigators. H.-U.W. provided valuable experiences for the field work from his prior primary care studies. All authors except C.P., J.M., and J.R. served as site principal investigators, organized and supervised fieldwork, and helped in data cleaning. C.P., JM and JR conceptualized the data analyses, helped in data cleaning and quality control, and conducted the quantitative and qualitative analyses. J.R. wrote a first draft of the paper, and all authors contributed to and approved of the final version.

Funding support: The study was financially supported by an investigator-initiated grant to the first author and the GWT-TUD (Gesellschaft 
für Wissens - und Technologietransfer der TU Dresden mbH - company with limited liabilities for transferring knowledge and technology of the Dresden University of Technology) by Lundbeck. Unassociated with this article, Allamani reports grants from Lundbeck during the conduct of the study and travel funds from Osservatorio Permanente Giovani e Alcool, Roma, Italy; Gual reports grants and personal fees from Lundbeck and DEA Pharma during the conduct of the study, grants from Teva, and personal fees from AbbiVie; Jakubczyk reports personal fees and nonfinancial support from Lundbeck and nonfinancial support from AstraZeneca, Sanofi Aventis, Polpharma, and Eli Lilly; Wittchen reports being an advisory board member for Hoffmann-La Roche, Lundbeck, and Servier; Landsmane reports personal fees and nonfinancial support from Lundbeck and Reckitt Benckiser (RB); Rehm reports grants from GWT-TUD during the conduct of the study, and grants, personal fees, and being a board member (Nalmefene) for Lundbeck; Wojnar reports personal fees from AOP Orphan, Berlin-Chemie, Janssen, Lundbeck, DEA Pharma, Chiesi, Reckitt Benckiser, Sanofi Aventis, and Servier; Struzzo reports grants from University of Dresden during the conduct of the study and being a primary care board member for Lundbeck.

Role of the sponsor: The study sponsor had no role in study design, collection, analysis, and interpretation of data. The study sponsor also had no role in writing of the report and the decision to submit the paper for publication.

Disclaimer: The views expressed in this article are solely those of the authors and not necessarily those of affiliated institutions or the funder.

Acknowledgments: The authors acknowledge all the primary care physicians for their invaluable contributions to this study, as well as Fabio Mariani (Italy 2), who helped in the data collection.

Supplementary materials: Available at http://www.AnnFamMed. org/content/13/1/28/suppl/DC1/.

\section{References}

1. Lim SS, Vos T, Flaxman AD, Danaei G, Shibuya K, Adair-Rohani H, et al. A comparative risk assessment of burden of disease and injury attributable to 67 risk factors and risk factor clusters in 21 regions, 1990-2010: a systematic analysis for the Global Burden of Disease Study 2010. Lancet 2012;380:2224-2260.

2. Shield KD, Rylett MJ, Gmel G, Rehm J. Trends in alcohol consumption and alcohol-attributable mortality in the EU in 2010. In: World Health Organization Regional Office for Europe, ed. Status Report on Alcohol and Health in 35 European Countries. Copenhagen, Denmark: WHO Regional Office for Europe; 2013:3-14.

3. Rehm J, Shield KD, Gmel G, Rehm MX, Frick U. Modeling the impact of alcohol dependence on mortality burden and the effect of available treatment interventions in the European Union. Eur Neuropsychopharmacol. 2013;23(2):89-97.

4. Rehm J, Mathers C, Popova S, Thavorncharoensap M, Teerawattananon $Y$, Patra J. Global burden of disease and injury and economic cost attributable to alcohol use and alcohol-use disorders. Lancet. 2009;373(9682):2223-2233.

5. American Psychiatric Association. Diagnostic and Statistical Manual of Mental Disorders. 4th ed. Washington, DC: American Psychiatric Association; 2000.

6. Rehm J, Shield KD, Rehm MX, Gmel G Jr, Frick U. Alcohol Consumption, Alcohol Dependence, and Attributable Burden of Disease in Europe: Potential Gains from Effective Interventions for Alcohol Dependence. Toronto, Canada: Centre for Addiction and Mental Health; 2012.

7. Alonso J, Angermeyer MC, Bernert S, Bruffaerts R, Brugha TS. Use of mental health services in Europe: results from the European Study of the Epidemiology of Mental Disorders (ESEMeD) project. Acta Psychiatr Scand. 2004;109(420):47-54.

8. Wittchen HU, Jacobi F, Rehm J, et al. The size and burden of mental disorders and other disorders of the brain in Europe 2010. Eur Neuropsychopharmacol. 2011;21(9):655-679.
9. Üstün BT, Sartorius N. Mental Illness in General Health Care: An International Study. West Sussex, England: John Wiley \& Sons; 1995.

10. Kessler RC, Ustün TB. The World Mental Health (WMH) Survey Initiative version of the World Health Organization (WHO) Composite International Diagnostic Interview (CIDI). Int J Methods Psychiatr Res. 2004;13(2):93-121.

11. Kessler RC, Barker PR, Colpe LJ, et al. Screening for serious mental illness in the general population. Arch Gen Psychiatry. 2003;60(2): 184-189.

12. Furukawa TA, Kessler RC, Slade T, Andrews G. The performance of the $\mathrm{K} 6$ and $\mathrm{K} 10$ screening scales for psychological distress in the Australian National Survey of Mental Health and Well-Being. Psychol Med. 2003;33(2):357-362.

13. Ustün TB, Chatterji S, Kostanjsek N, et al.; WHO/NIH Joint Project. Developing the World Health Organization Disability Assessment Schedule 2.0. Bull World Health Organ. 2010;88(11):815-823.

14. Üstün TB, Kostanjsek N, Chatterji S, Rehm J, eds. Measuring Health and Disability: Manual for WHO Disability Assessment Schedule WHODAS 2.0. Geneva, Switzerland: World Health Organization; 2010.

15. UKATT Research Team. Cost effectiveness of treatment for alcohol problems: findings of the randomised UK alcohol treatment trial (UKATT). BMJ. 2005;331(7516):544.

16. Manthey J, Gual A, Jakubczyk A, et al. Alcohol dependence in primary care in Europe (APC) study: design, instruments and patient characteristics. Toronto, Canada: Center for Addiction and Mental Health; 2014.

17. Samokhvalov AV, Popova S, Room R, Ramonas M, Rehm J. Disability associated with alcohol abuse and dependence. Alcohol Clin Exp Res. 2010;34(11):1871-1878.

18. Rehm J, Anderson P, Barry J, et al. Prevalence of and potential influencing factors for alcohol dependence in Europe. Eur Addict Res. 2014;21(1):6-18.

19. Wittchen HU, Glaesmer H, März W, et al.; DETECT-Study Group. Cardiovascular risk factors in primary care: methods and baseline prevalence rates-the DETECT program. Curr Med Res Opin. 2005;21(4):619-630.

20. Creavin ST, Creavin AL, Mallen CD. Do GPs respond to postal questionnaire surveys? A comprehensive review of primary care literature. Fam Pract. 2011;28(4):461-467.

21. Wittchen HU. Reliability and validity studies of the WHOComposite International Diagnostic Interview (CIDI): a critical review. J Psychiatr Res. 1994;28(1):57-84.

22. Kaner EF, Beyer F, Dickinson HO, et al. Effectiveness of brief alcohol interventions in primary care populations. Cochrane Database Syst Rev. 2007;18(2):CD004148.

23. O'Donnell A, Anderson P, Newbury-Birch D, et al. The impact of brief alcohol interventions in primary healthcare: a systematic review of reviews. Alcohol Alcohol. 2014;49(1):66-78.

24. Rösner S, Hackl-Herrwerth A, Leucht S, Vecchi S, Srisurapanont M, Soyka M. Opioid antagonists for alcohol dependence. Cochrane Database Syst Rev. 2010;12(12):CD001867.

25. Rösner S, Hackl-Herrwerth A, Leucht S, Lehert P, Vecchi S, Soyka M. Acamprosate for alcohol dependence. Cochrane Database Syst Rev. 2010;9(9):CD004332.

26. Gilchrist G, Moskalewicz J, Slezakova S, et al. Staff regard towards working with substance users: a European multi-centre study. Addiction. 2011;106(6):1114-1125.

27. Urada D, Teruya C, Gelberg L, Rawson R. Integration of substance use disorder services with primary care: health center surveys and qualitative interviews. Subst Abuse Treat Prev Policy. 2014;9:15.

28. Deveugele M, Derese A, van den Brink-Muinen A, Bensing J, De Maeseneer J. Consultation length in general practice: cross sectional study in six European countries. BMJ. 2002;325(7362):472.

29. Nutt DJ, Rehm J. Doing it by numbers: a simple approach to reducing the harms of alcohol. J Psychopharmacol. 2014;28(1):3-7.

30. Probst C, Manthey J, Gual A, Wojnar M, Rehm J. Why do patients not seek treatment? An empirical investigation based on data from a large European study in primary care practices. Toronto, Canada: Center for Addiction and Mental Health; 2014. 